\title{
Secure weight management through fitting circadian patterns of physical activity, resting and eating
}

\begin{abstract}
This public health article develops a feasible global strategy to effectively manage body weight and prevent obesity through circadian fitting of physical activity, rest and eating. The special emphasis is placed on the circadian nature of such a fitness to avoid building obesity upon negligible but quite devastating daily weight gains. Thus, with no necessity to compromise life satisfaction and quality by overly limiting eating, resting and exercising, this doable program minimizes risks from obesity, diabetes, metabolic syndrome and related cardiovascular complexities.
\end{abstract}

Keywords: weight management, circadian pattern, physical activity, rest, eating
Volume 2 Issue 4 - 2015

\author{
Akbar Nikkhah \\ Department of Animal Sciences, University of Zanjan, Iran
}

Correspondence: Akbar Nikkhah, Chief Highly Distinguished Professor, Department of Animal Sciences \& Faculty of Agricultural Sciences, University of Zanjan, Iran, Email anikkha@yahoo.com

Received: April 21, 2015 | Published: May 09, 2015

\section{Strategy development and critiques}

Debate has long existed on the optimal strategies of weight management and control to avoid obesity. But, no single program has been developed to enable effective management of energy balance and successful prevention of obesity. Recently, efforts have been made to draw attention towards adequate physical activity mainly on a weekly and in some cases on daily bases. But, the fact is that none of these programs and guidelines works optimal for the general world population with unique individual life style and food regime. Therefore, public health programs continue to strive for a feasible approach that can take into account such inter-person variations and even intra-person fluctuations in life style. ${ }^{1-4}$ Any successful philosophy must stem from establishing rhythmic regularities in gene, cell, tissue, organ and whole body physiology crucially on a circadian basis. ${ }^{5,6}$ This is simply because human cells have evolved to function optimally on a 24-h cycle, following the surrounding nature..$^{7-9}$

This article, thus, aims to eradicate the above-mentioned limitation of the health programs developed to-date through establishment of a global practicable strategy that accomplishes the complex task of weight management and control on each and every 24-h phase of life. A major critique of weight control strategies is that until unless the job is not well-done on a circadian basis, it will not prove promising and accountable. For health benefits to be realized, such a daily accomplishment of weight management must be secured. ${ }^{5,6}$

In a nutshell, harmonies among eating, resting and physical activity rhythms must be reached on daily basis. This means that if the timing or duration of any of the three determinants changes on any given day, the timing and duration of the others must also harmonically change. For instance, during any certain $24 \mathrm{hr}$ phase, if for any reason, energy intake significantly increases, then accordingly, resting must equally decrease and physical activity must sufficiently increase to not carry any unwanted weight gain on the next day. This plan must be extended to all days and be practiced regularly. Should be done so, the strategy works optimal in efficacious weight management and obesity prevention. Public education on such a health program must be persistently pursued and where applicable, explanations on circadian budgeting of energy balance equivalents from eating, resting and physical activity must be provided.

\section{Implication}

Effective body weight management is guaranteed by circadian fitting of eating, resting and physical activity rhythms. No other strategy, particularly in longer terms, can accomplish the same great success. The task must be accomplished on each and every day.

\section{Acknowledgements}

Gratitude goes to Iran's Ministry of Science Research and Technology, National Elite Foundation and University of Zanjan for supporting the author's global programs of optimizing science edification in the third millennium.

\section{Conflict of interest}

The author declares no conflict of interest.

\section{References}

1. Nikkhah A. Harmonizing Eating and Exercise Circadian Rhythms for Optimal Glucose-Insulin and Vascular Physiology. Int J Diabetol Vasc Dis Res. 2015;3(3):87-88.

2. Nikkhah A. Eating time modulations of physiology and health: life lessons from human and ruminant models. Iran J Basic Med Sci. 2012;15(4):891-899.

3. Nikkhah A. Breast safety progress through exercise-driven lactation: A pragmatic bioprocess to prevent cancer. J Bioproces Biotech. 2015;5:3.

4. Nikkhah A. Effective weight management in periparturient women through optimizing eating timing: A Novel Global Approach. Adv Weight Manag Obesity Control. 2015:2(3):00018.

5. Nikkhah A. Circadian fitting of exercise and eating patterns: The secret of healthy life. J Bioprocess Biotech. 2015;5:e129.

6. Nikkhah A. Establishing rhythmic regularities in cell physiology: A novel global program to thwart cancer. J Nutr Health Food Eng. 2015.

7. Sehgal A. Molecular Biology of Circadian Rhythms. USA: John Wiley \& Sons Inc; 2004. 283 p.

8. Nikkhah A. Science of eating time: A novel chronophysiological approach to optimize glucose-insulin dynamics and health. $J$ Diabetes Mellitus. 2011;2(1):8-11.

9. Nikkhah A. Eating timing and diabetes. Int J Diabetol Vas Dis Res. 2014;2(2):1. 